\title{
HYDROGELS FROM ACRYLIC ACID WITH N,N-DIMETHYLACRYLAMIDE: SYNTHESIS, CHARACTERIZATION, AND WATER ABSORPTION PROPERTIES.
}

\author{
S. AMALIA POOLEY*(l), BERNABÉ L., RIVAS ${ }^{(1)}$, FELIPE E. LILLO ${ }^{(1)}$, GUADALUPE DEL C. PIZARRO (2) \\ (1) Polymer Department, Faculty of Chemistry of the Concepción, Casilla 160-C, Concepción, Chile. apooley@udec.cl. \\ ${ }^{(2)}$ Department of Chemistry, Technological Metropolitan University, J. P. Alessandri 1242, Santiago, Chile
}

(Received: November 10, 2009 - Accepted: January 25, 2010)

\begin{abstract}
Copolymer hydrogels of acrylic acid (AA) with $N, N$-dimethylacrylamide (NNDMAAm) were synthesized by solution free radical polymerization at different feed mol monomer ratios. The monomer reactivity ratios were determined by Kelen-Tüdös method. According to that, the monomer reactivity ratios for poly(AAco-NNDMAAm) were $\mathrm{r}_{1}=0.650\left(\mathrm{M}_{1}=\mathrm{AA}\right)$ and $\mathrm{r}_{2}=1.160\left(\mathrm{M}_{2}=\right.$ NNDMAAm $),\left(\mathrm{r}_{1} \times \mathrm{r}_{2}=0.753\right)$.

The effect of reaction parameters including: the concentration of cross-linking reagent, monomer concentration, $\mathrm{pH}$, temperature, salt solutions, and solvent polarity on the water absorption have been studied. The hydrogels achieved water-absorption values of $544 \mathrm{~g}$ water/ $\mathrm{g}$ xerogel for the copolymer poly(AA-coNNDMAAm) 3:1 at pH 5. Low critical solution temperature (LCST) values of hydrogels, showed an increase when the hydrophilic AA moiety content increased in the copolymers.
\end{abstract}

Keywords: copolymerization, gels, swelling, crosslinking, water absorption.

\section{INTRODUCTION}

In recent years, considerable research attention has been focused on intelligent polymer materials, especially hydrogels that contain functional groups and are able to alter their volume or other properties in response to environmental stimuli, such as $\mathrm{pH}$, temperature and electric field, among others $(1-2)$.

Hydrogels are cross-linked three-dimensional hydrophilic polymer networks that swell but do not dissolve when brought into contact with water. Hydrogels are a class of polymeric materials with the ability to hold a substantial amount of water, presenting a soft, rubbery-like consistency, and low interfacial tension parameters ${ }^{(3-8)}$. Hydrogels properties mainly depend on the degree of cross-linking, the chemical composition of the polymeric chains, and the interaction between the network and surrounding liquids. ${ }^{(3)}$. Hydrophilicity or high water retention in hydrogels is attributed to the presence of hydrophilic groups, such as carboxylic acids, amides, and alcohols ${ }^{(3-4)}$.

The structural features of these materials dominate its surface properties, permeselectivity and permeability, giving hydrogels their unique, interesting properties, and the similarity of their physical properties to those present in living tissues ${ }^{(5,6)}$.

The important swelling of hydrogels based on acrylic acid is facilitated by the presence of carboxylic acid groups in the polymer chain, which are strongly associated with water molecules. These groups are readily ionisable and sensitive to the effects of $\mathrm{pH}$ and ionic strength. Thus, the equilibrium swelling of AA copolymers are affected by the solution's $\mathrm{pH}$ and ionic strength in which they are swelled ${ }^{(9-11)}$.

Polymer gels play an important role in many emerging technological areas such as drug delivery, sensors, and superabsorbent materials.

Copolymerization reaction of two monomers is an effective method to modify the physical properties of polymer gels ${ }^{(12-15)}$.

Several authors have studied the Low Critical Solution Temperature (LCST) in poly(isopropyl acrylamide) hydrogels (PNIPAAm) and reported that incorporation of an hydrophilic comonomer leads to a higher values of LCST, while incorporation of a hydrophobic monomer decreases the Low Critical Solution Temperature ${ }^{(16-18)}$. A good balance between hydrophilic and hydrophobic interactions in the polymer, explains this sharp phase transition (19).

The transition temperature of the cross-liked gels changed according to the feed monomer ratio used in the copolymerization reaction. The $\mathrm{pH}$ value of the solution strongly affected the swelling ratio ${ }^{(19-22)}$.

Several methods to detect LCST have been reported, including light scattering to detect the coil-to-globule transition (23-24), turbidimetric measurements to achieve phase transition or differential scanning calorimetry (DSC) to measure the transition heat ${ }^{(25-27)}$.

Hydrogels are also used in pharmacological applications, in controlled release ${ }^{(27)}$, water purification, drug release system, and others. ${ }^{(3-15)}$
We have previously published ${ }^{(28-30)}$ the synthesis and swelling properties of hydrogels from functional vinyl monomers. These systems showed that the copolymers containing acrylic acid and acrylamide derivative moieties are very sensitive to stimuli as $\mathrm{pH}$, temperature, ionic strength, and copolymer composition. Thus, the influence of water absorption at room temperature was strong at $\mathrm{pH} 5$ and $\mathrm{pH} 7$, with maximums between 1200 and $1600 \%$, when the poly(2-hydroxyethylmethacrylate-co-maleoylglycine) P(HEMA-co-MG) was richest in HEMA monomer unit.

The aim of this paper is to synthesize by solution, free radical polymerization copolymers of acrylic acid (AA) with $N, N \phi$-dimethylacrylamide (NNDMAAm), at different feed monomer ratios and degrees of cross-linking, and to study the swelling properties of these hydrogel systems in distilled water and ethanol at different $\mathrm{pH}$, temperature, time, and salt concentration. The thermal properties of the copolymers, specially the glass transition temperatures $(\mathrm{Tg})$, and the thermal decomposition will also be determined.

\section{EXPERIMENTAL}

Materials

Acrylic acid (AA; Aldrich) and N'N-dimethylacrylamide (NNDMAAm; Aldrich) were purified by distillation. All the other reagents were used as received, without further purification.

Preparation of poly(acrylic acid-co- $N^{\prime} \mathrm{N}$-dimethylacrylamide), P(AA-coNNDMAAm)

Cross-linked poly(AA-co-NNDMAAm) hydrogels, containing 25, 33, 50, 66 , and $75 \mathrm{~mol}-\%$ of AA were prepared by solution free radical polymerization. AA was dissolved in water and then NNDMAAm, MBA, and APS were added to the AA solution. Following, the reaction solution was heated and polymerized for 24 hours at $70^{\circ} \mathrm{C}$ in a Teflon tube of $40 \mathrm{~mm}$ diameter. The product was cut into small discs $5 \mathrm{~mm} \times 20 \mathrm{~mm}$ and dried until constant weight. Finally, the dried product was characterized and the swelling properties were determined.

The feed mol ratios of AA and NNDMAAm were 1:1; 1:2;1:3, 2:1, and $3: 1$. The total weight percentage of both monomers in the solution was 15 mol- $\%$. The weight percentage of the cross-linking reagent with respect to the monomers was 1 and 0.5 mol- $\%$. The weight percentage of the initiator with respect to the monomers was always $1 \mathrm{~mol}-\%$.

Hydrogel characterization

The dried copolymers were grounded to a suitable sized powder for FT-IR analysis. The FT-IR spectra of the copolymers were obtained by using a Magna Nicolet IR-550 spectrophotometer.

The thermogravimetry analysis of the copolymers was performed by using TGA (Polymer Laboratories, STA-625 thermobalance). Measurements on 5 $\mathrm{mg}$ of dry samples were carried out through a heating rate of $10{ }^{\circ} \mathrm{C} / \mathrm{min}$, from room temperature to $550^{\circ} \mathrm{C}$ under nitrogen atmosphere.

Copolymer morphology was examined by scanning electron microscopy (SEM) (Jeol, GSM-6380LV). 
The elemental analyses were carried out using an 1108 FISON CE analyzer (Italy).

The contact angle has been measured using a Gionometer model 100-00230 , Series 3064 by placing a drop of water on an hydrogel disk surface. The measurement was made in less than 20 seconds (as a maximum time), because the highly hydrophilic samples rapidly absorbed the drop deposited on the surface.

Swelling measurements

The sample of poly(AA-co-NNDMAAm) $(0.5 \mathrm{~g})$ was immersed in 400 $\mathrm{mL}$ of distilled water for 12 hours until equilibrium was reached, at room temperature. The swollen gel was weighed after the excess surface solution was removed by filter paper. The absorbency was calculated using the following equation:

$\mathrm{Q}=\left(\mathrm{W}_{2}-\mathrm{W}_{1}\right) / \mathrm{W}_{1}$

Absorbency $(\mathrm{Q})$ is expressed in grams of liquid retained in the gel per grams of dry copolymer. $\mathrm{W}_{2}$ and $\mathrm{W}_{1}$ are the weights of the swollen gel and the dry poly(AA-co- NNDMAÁm), respectively.

Effect of time, temperature, and $p H$ on absorbency

The methods were the same that were used for the swelling measurements in twice-distilled water, saline solution, and ethanol. The $\mathrm{pH}$ values of the solution were adjusted with dilute $\mathrm{HCl}$ or $\mathrm{NaOH}$.

Water retention capacity

The hydrogels were placed in twice-distilled water for one day. The swollen gels that reached equilibrium in water, were drained in nylon bags for one day. Then, the gels and the bags were put into an oven and heated at constant temperature. To investigate the weight variation, they were weighed at one-day intervals.

\section{RESULTS AND DISCUSSION}

Synthesis and characterization

The copolymers were synthesized by free radical polymerisation. The general structure is shown below:

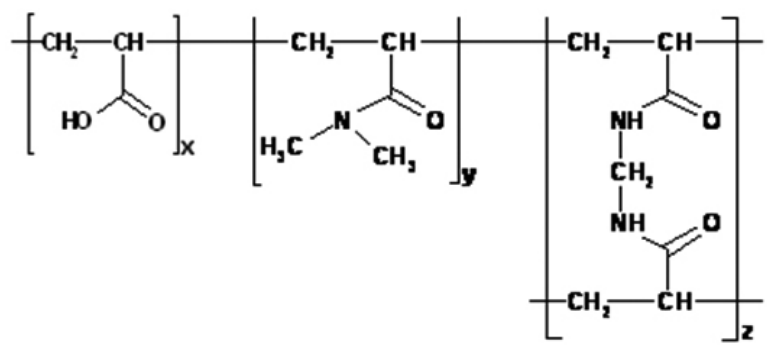

The yield for all copolymers was higher than $90 \%$ (see Table I).

Table I. Experimental conditions of the copolymerization reaction and yield of poly(AA-co- NNDMAAm), 1 mol- $\%$ MBA and 1 mol- $\%$ PSA.

\begin{tabular}{|c|c|c|c|c|c|c|}
\hline $\begin{array}{c}\text { Polymer } \\
\text { sample } \\
\text { No }\end{array}$ & $\begin{array}{c}\text { Feed } \\
\text { monomer } \\
\text { ratio (in } \\
\text { mol) }\end{array}$ & $\begin{array}{c}{[\mathrm{AA}]} \\
(\mathrm{mol})\end{array}$ & $\begin{array}{c}\text { [NNDMAAm] } \\
(\mathrm{mol})\end{array}$ & $\begin{array}{c}{[\mathrm{MBA}]} \\
(\mathrm{mol})\end{array}$ & $\begin{array}{c}{[\mathrm{PSA}]} \\
(\mathrm{mol})\end{array}$ & $\begin{array}{c}\text { Yield } \\
(\%)\end{array}$ \\
\hline 1 & $(1: 1)$ & 0.0222 & 0.0222 & $4.43 \times 10^{-4}$ & $4.43 \times 10^{-4}$ & 90 \\
\hline 2 & $(1: 2)$ & 0.0148 & 0.0295 & $4.43 \times 10^{-4}$ & $4.43 \times 10^{-4}$ & 97 \\
\hline 3 & $(1: 3)$ & 0.0111 & 0.0332 & $4.43 \times 10^{-4}$ & $4.43 \times 10^{-4}$ & 96 \\
\hline 4 & $(2: 1)$ & 0.0295 & 0.0148 & $4.43 \times 10^{-4}$ & $4.43 \times 10^{-4}$ & 95 \\
\hline 5 & $(3: 1)$ & 0.0332 & 0.0111 & $4.43 \times 10^{-4}$ & $4.43 \times 10^{-4}$ & 92 \\
\hline
\end{tabular}

Hydrogels obtained are transparent, smooth, and maintain their shape in the swollen state.

Figure 1 shows the FT-IR spectra for the five copolymers poly(AA-coNNDMAAm). The spectra show the typical absorption bands of the both comonomers and the cross-linking reagent. Among the most characteristic absorption bands are the following (in $\left.\mathrm{cm}^{-1}\right): 3450-3200(\mathrm{O}-\mathrm{H}$ stretching of acid group); 2940, 2810 (C-H stretching, aliphatic.); 1790,1640 ( $\mathrm{C}=\mathrm{O}$ group ester); 1643,1550 (N-H deformation of amide group); 1219, 1034, 626 (stretching).

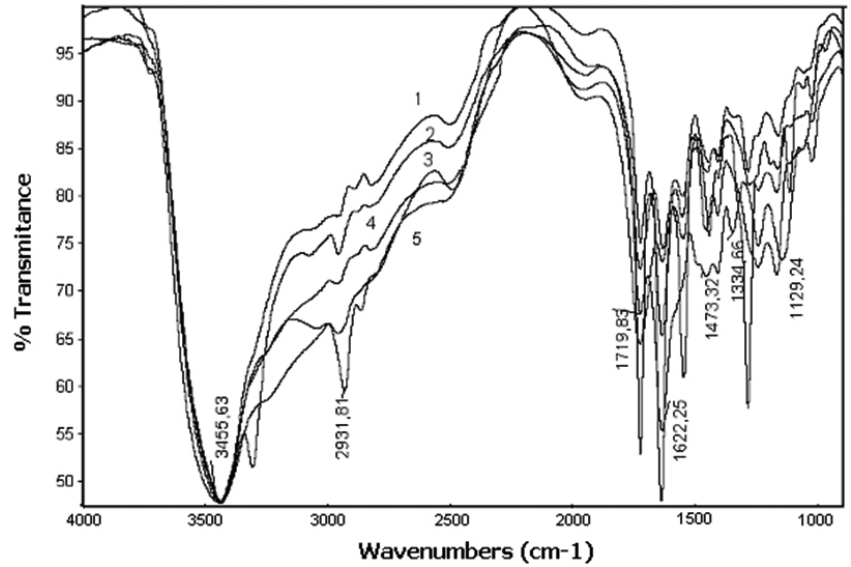

Figure 1. FTIR (KBr) spectra for poly(AA-co-NNDMAAm) 1:1(1); 1:2(2); 2:1(3); and 1:3(4); 3:1(5) / 1 mol- $\%$ MBA.

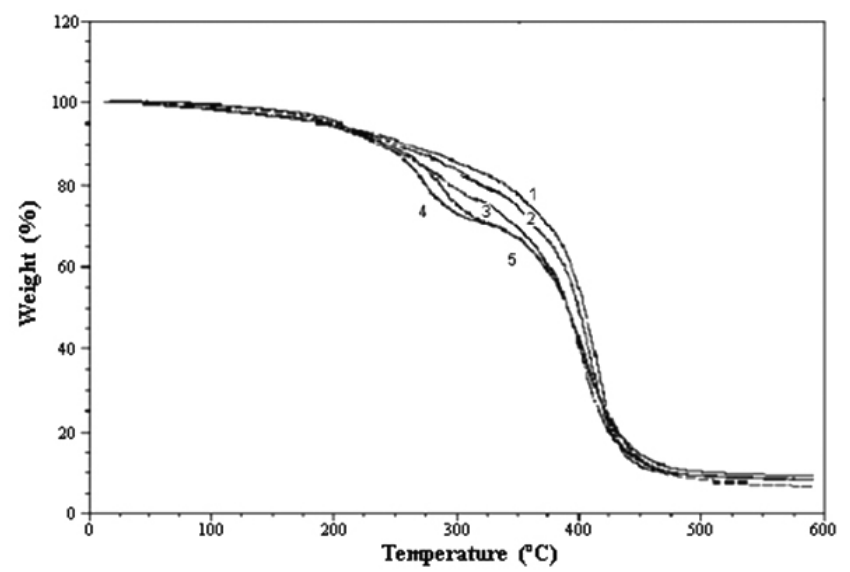

Figure 2. Thermal behaviour of poly(AA-co-NNDMAAm) 1:1(1); 1:2(2); 2:1(3); 1:3(4); and 3:1(5) / 1 mol- $\% \mathrm{MBA}$, heating rate: $10^{\circ} \mathrm{C}$ min $^{-1}$ under $\mathrm{N}_{2}$.

The thermograms of all polymers show a typical sigmoidal shape. All the copolymers are stable up to $200^{\circ} \mathrm{C}$ with a weight loss lower than $10 \%$ at $220^{\circ} \mathrm{C}$ (see Figure 2).

Thescanning electronmicrograph of poly(AA-co-NNDMAAm) 1:1, showsa smooth morphology (see Figure 3).

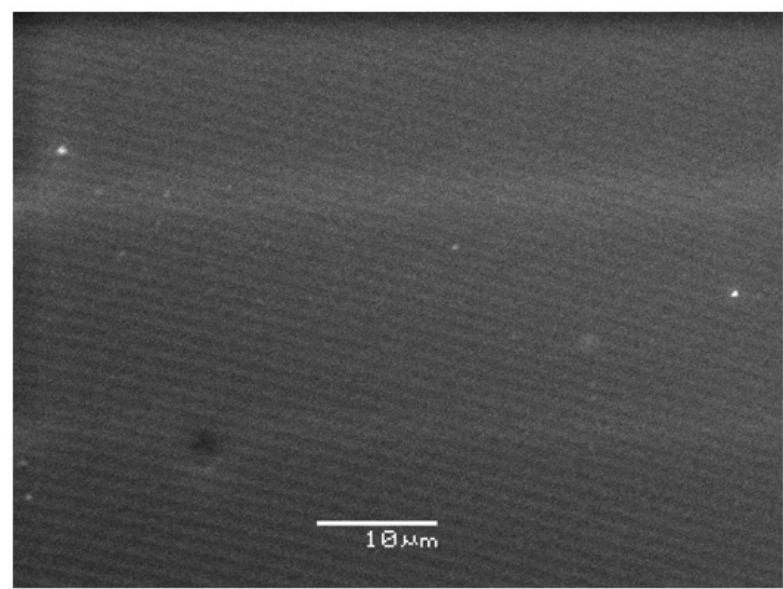

Figure 3. SEM micrograph of poly(AA-co-NNDMAAm) $1: 1 / 1$ mol- $\%$ MBA (2000x) 
Monomer reactivity ratios, (MRR)

The monomer reactivity ratio values for the monomers NNDMAAm and $\mathrm{AA}$, were determined from the monomer feed ratios and the copolymers composition according to Kelen Tüdös (K-T) method (31). Copolymers composition were determined from elemental analysis data (see Table 2).

Table II. Elemental analysis, relationship N/C and copolymers composition.

\begin{tabular}{|c|c|c|c|c|c|}
\hline \multirow{2}{*}{$\begin{array}{c}\text { M1,(AA) } \\
\text { (mol-\%) } \\
\text { In the feed }\end{array}$} & \multicolumn{4}{|c|}{$\begin{array}{c}\text { Elemental Analysis } \\
\text { Found (calculated) value \% }\end{array}$} \\
\hline M1:M2 & $\begin{array}{c}\text { copolymer } \\
(\mathbf{m 1})\end{array}$ & Nitrogen & Carbon & Hydrogen & Ratio N/C \\
\hline $3: 1$ & 70.24 & 4.506 & 46.680 & 9.697 & 0.0965 \\
\hline & & $\mathbf{5 . 2 0 3}$ & $\mathbf{5 3 . 8 9 7}$ & $\mathbf{6 . 9 0 4}$ & $\mathbf{0 . 0 9 6 5}$ \\
\hline $2: 1$ & 60.77 & 5.882 & 48.663 & 10.315 & 0.1209 \\
\hline & & $\mathbf{6 . 6 4 6}$ & $\mathbf{5 4 . 9 7 8}$ & $\mathbf{7 . 2 6 7}$ & $\mathbf{0 . 1 2 0 9}$ \\
\hline $1: 1$ & 46.73 & 7.421 & 48.568 & 10.870 & 0.1528 \\
\hline & & $\mathbf{8 . 6 2 8}$ & $\mathbf{5 6 . 4 6 2}$ & $\mathbf{7 . 7 6 6}$ & $\mathbf{0 . 1 5 2 8}$ \\
\hline $1: 2$ & 29.38 & 9.613 & 51.509 & 11.920 & 0.1866 \\
\hline & & $\mathbf{1 1 . 4 5 1}$ & $\mathbf{5 8 . 5 7 5}$ & $\mathbf{8 . 3 2 5}$ & $\mathbf{0 . 1 8 6 6}$ \\
\hline $1: 3$ & 22.10 & 10.185 & 51.106 & 11.899 & 0.1993 \\
\hline & & $\mathbf{1 2 . 3 8 2}$ & $\mathbf{5 9 2 7 2}$ & $\mathbf{8 . 7 1 1}$ & $\mathbf{0 . 1 9 9 3}$ \\
\hline
\end{tabular}

M1: Initial composition of monomer 1 (AA), m1: copolymer composition of monomer 1 (AA)

To determine the monomer reactivity ratios, a plot of monomer feed composition $\left(\mathrm{M}_{1}\right)$ vs monomer composition in the copolymer $\left(\mathrm{m}_{1}\right)(\mathrm{mol}-\mathrm{\%})$ for $\mathrm{AA}$, is shown in Figure 4 for poly(AA-co-NNDMAAm).

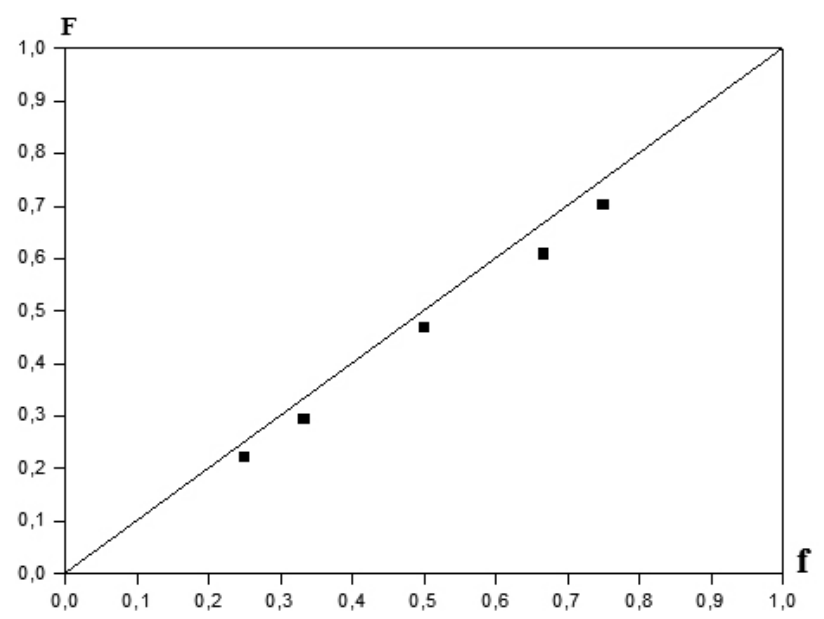

Figure 4. Relationship of M1 in the feed (M1) and in the copolymer (m1). The Kelen Tüdös equation (1) is symmetrically transformed into:

$$
G=r_{1} \times F-r_{2}
$$

by introducing the new parameters $\mathrm{x}, \mathrm{h}$, and $\alpha=\left(F_{\text {min }} \times F_{\text {max }}\right)^{0.5}$ , where $\mathrm{F}_{\min }$ and $\mathrm{F}_{\max }$ correspond to the smallest and largest fraction in the copolymer $(\mathrm{F})$ that are calculated, respectively (see Table 3 ).

Table III. Reactivity ratios of AA and NNDMAAm in poly(AA-co-NNDMAAm) by Kelen Tüdös for high conversion method, $\mathrm{m}=1,37565917$, a = 1,44529.

\begin{tabular}{|c|c|c|c|c|c|c|c|c|c|c|c|}
\hline Charge (mol-\%) & \multicolumn{2}{|l|}{ Copolymer } & \multicolumn{2}{l|}{ Conversion } & & & & & & & \\
\hline $\mathrm{M1}^{(\mathrm{a})}$ & $\mathrm{m}^{(\mathrm{b})}$ & ${\text { wt.- } \%{ }^{(\mathrm{c})}}$ & $\mathrm{Xo}$ & $\mathrm{y}$ & $\delta_{1}$ & $\delta_{2}$ & $\mathrm{Z}$ & $\mathrm{F}$ & $\mathrm{G}$ & $\xi$ & $\eta$ \\
\hline 75.0 & 70.2 & 47.4 & 3.000 & 2.360 & 0.437 & 0.556 & 0.709 & 4.701 & 1.92 & 0.7648 & 0.312 \\
\hline 66.7 & 60.8 & 49.5 & 2.000 & 1.549 & 0.442 & 0.571 & 0.690 & 3.256 & 0.9 & 0.6925 & 0169 \\
\hline 50.0 & 46.8 & 46.9 & 1.000 & 0.879 & 0.434 & 0.494 & 0.836 & 1.258 & -0.15 & 0.4655 & -0.954 \\
\hline 33,3 & 29.4 & 50.0 & 0.500 & 0.416 & 0.435 & 0.523 & 0.772 & 0.699 & -0.76 & 0.3259 & -0.363 \\
\hline 25,0 & 22.1 & 49.0 & 0.333 & 0.284 & 0.429 & 0.504 & 0.798 & 0.444 & -0.89 & 0.2352 & -0.474 \\
\hline
\end{tabular}

a) Monomer composition in feed mol-; b) Copolymer composition of $\mathrm{M}_{1}$ in $\mathrm{mol}-\mathrm{\%}$

c) Conversion

The transformed variables are defined as:

$\mathrm{h}=\mathrm{G} /\left(\mathrm{r}_{1}+\mathrm{r}_{2} / \mathrm{a}\right) \quad \mathrm{x}=\mathrm{F} /(\mathrm{a}+\mathrm{F})$

The $r_{1}$ and $r_{2}$ values were also determined according to Equation (2):

$\mathrm{h}=\left(\mathrm{r}_{1}+\mathrm{r}_{2} / \mathrm{a}\right) \mathrm{x}$

(2)

Where, $\mathrm{h}$ and $\mathrm{x}$ are mathematical functions of the monomer molar ratios in the feed and in the copolymer respectively, a is an arbitrary denominator with any positive value, which produces a more homogeneous distribution of data along $\mathrm{h}-\mathrm{x}$ axes.

The parameters $\mathrm{x}, \mathrm{h}$ and a have been previously defined: $\mathrm{G}=\left(\mathrm{m} / \mathrm{m}_{2}-1\right) / \mathrm{z}$ and $\mathrm{F}=\left(\mathrm{m}_{1} / \mathrm{m}_{2}\right) / \mathrm{z}^{2} ; \mathrm{z}=\log \left(1-\mathrm{d}_{1}\right) / \log \left(1-\mathrm{d}_{2}\right) ; \mathrm{d}_{1}=\mathrm{d}_{2} \mathrm{y} / \mathrm{X}_{\mathrm{o}} ; \mathrm{d}_{2}=\mathrm{wt}-\mathrm{O}\left(\mathrm{m}+\mathrm{X}_{\mathrm{o}}\right) /$ $(\mathrm{m}+\mathrm{y}) / 100 ; \mathrm{m}=\mathrm{m}_{2} / \mathrm{m}_{1} ; \mathrm{y}=\mathrm{m}_{1} / \mathrm{m}_{2} ; \mathrm{X}=\mathrm{M}_{1} / \mathrm{M}_{2} ; \mathrm{wt}-\%=$ conversion; $\mathrm{m}_{1}$ and $\mathrm{m}_{2}$ are the molecular weights of monomers 1 and 2 respectively; $\mathrm{M}_{1}$ and $\mathrm{M}_{2}=$ initial composition of monomers in mol, $\mathrm{M}_{1}=(\mathrm{AA})$ and $\mathrm{M}_{2}=(\mathrm{NNDMAAm})$; $\mathrm{m}_{1}$ and $\mathrm{m}_{2}=$ correspond to the monomer composition in the copolymer for each monomer. The variable $\mathrm{x}$ can take any possible value in the 0 -to- 1 interval. A plot of hvs $\mathrm{x}$ gives a straight line, which on extrapolation to $\mathrm{x}=0$ and $\mathrm{x}=1$ gives $-r_{2} / a$ and $r_{1}$, respectively (see Figure 5).

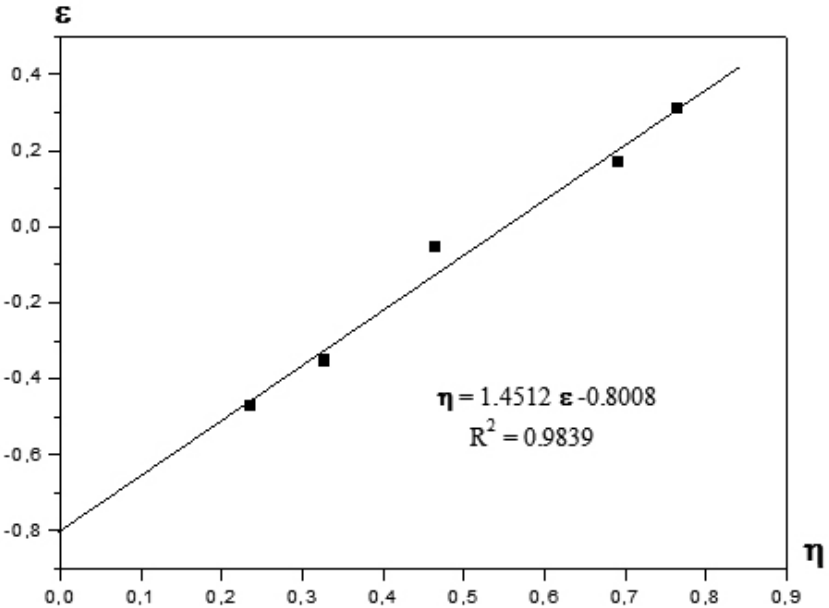

Figure 5. $\mathrm{h}$ vs $\mathrm{x}$ representation of the copolymerization parameters of poly(AA-co-NNDMAAm) by K-T method. 
According to these values, the monomer reactivity ratios for poly(AA-coNNDMAAm) are the following: $r_{1}=0.650$ and $r_{2}=1.160,\left(r_{1} \times r_{2}=0.753\right)$. According to the results obtained from the data, these copolymers would mainly correspond to random copolymers.

For poly(AA-co-NNDMAAm) system, the results in general suggest that the chain growth reactions proceeds predominantly by the addition of AA monomer to the $\sim$ R-NNDMAAm macro-radical, where NNDMAAm also produces random copolymers.

Low Critical Solution Temperature (LCST)

It is found that aqueous solutions of these copolymers exhibited a lower critical solution temperature (LCST), depending on their chemical composition, followed by coacervate formation above the LCST. Furthermore, thermosensitive hydrogels could be prepared by free radical copolymerization of AA and NNDMAAm in the presence of the crosslinker reagent MBA and initiator PSA. The poly(AA-co-NNDMAAm) 2:1 and 1:1 showed a LCST $72.6^{\circ} \mathrm{C}$ and $67.5^{\circ} \mathrm{C}$ respectively, which are significantly higher than poly(NIPAAm) $)^{(18)}$.

With an increase of NNDMAAm in the copolymer, the phase transition temperature decreased due to the decreased hydrophilic balance (see Figure 6). The LSCT increased with an increase in the hydrophilic component of AA in the copolymer.

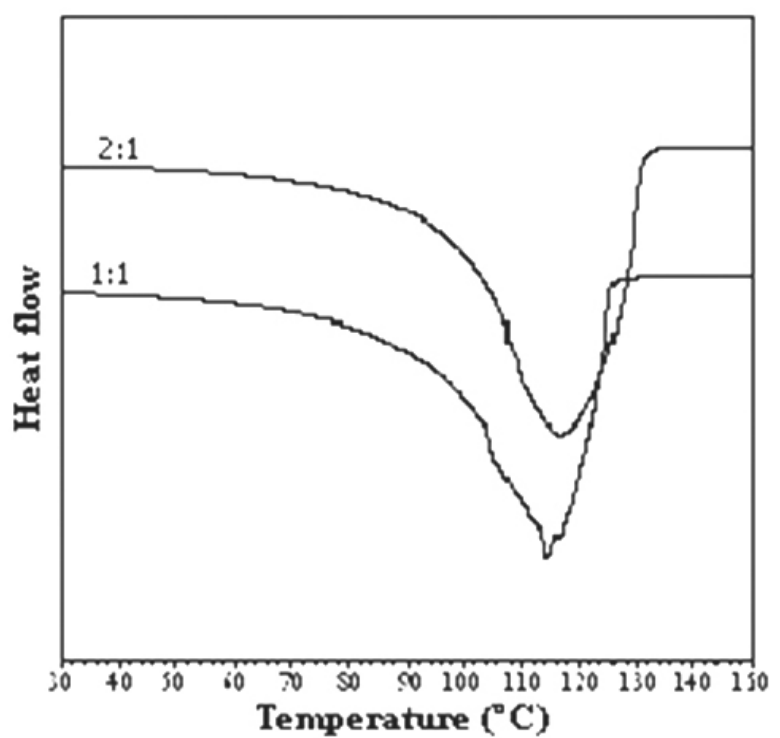

Figure 6. DSC Thermograms of poly(AA-co-NNDMAAm) 2:1 and 1:1 respectively. Heating rate: $10^{\circ} \mathrm{C} / \mathrm{min}$.

Contact angle $\mathrm{T}$

he contact angles were determined for all copolymers. Following are the some values obtained for the contact angles for the poly(AA-co-NNDMAAm) at $1 \mathrm{~mol}-\%$ MBA :

For the $3: 1$ feed monomer ratio, the value was $38^{\circ}$; for the $1: 1$ ratio, the value $42^{\circ}$; for the $1: 3$ ratio, the value was $46^{\circ}$. According to the results, the value of the contact angle increases as the copolymer becomes richer in NNDMAAm, which is a non ionisable group, therefore, it decreases its affinity for water.

Absorbency

Hydrogel absorbency in distilled water for five feed mol ratios is shown in Figure 7. Poly(AA-co-NNDMAAm) 3:1 showed the highest absorption of water, in twice-distilled water. This result is due to the gradual diffusion of water molecules into the network of the hydrogel and the complete filling or occupation of the pre-existing or dynamically formed spaces in the polymer chains.

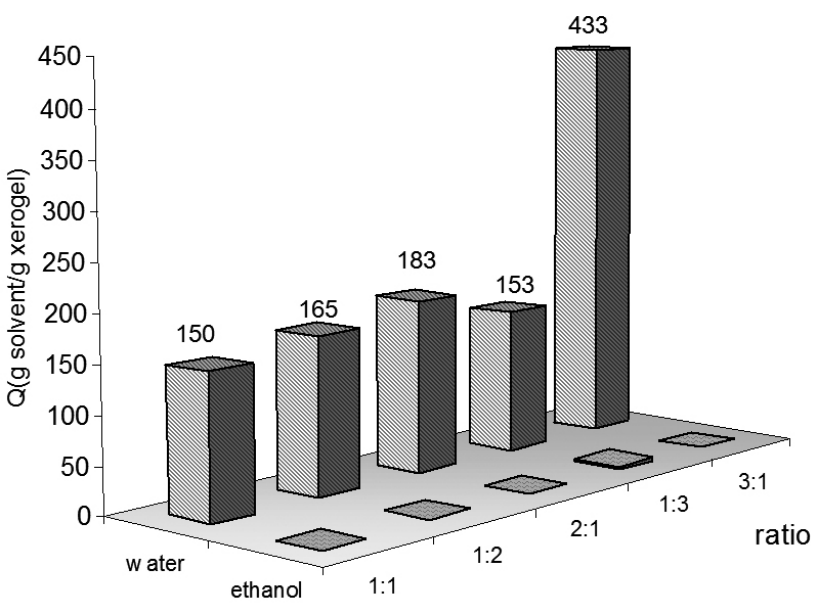

Figure 7. Absorption (Q) of poly(AA-co-NNDMAAm) 1:1; 1:2; 2:1; 1:3; $3: 1 / 1$ mol- $\%$ MBA in twice-distilled water and ethanol at room temperature.

The absorbency of poly(AA-co-NNDMAAm) 3:1 / 0.5 mol- $\%$ MBA, is higher than the absorbency of poly(AA-co-NNDMAAm) $3: 1 / 1$ mol- $\%$ MBA in twice-distilled water at room temperature, showing neither of them absorbency in ethanol (see Figure 8). This result is due to the smaller amount of cross-linking incorporated into the backbone, which increases the space for the water molecules.

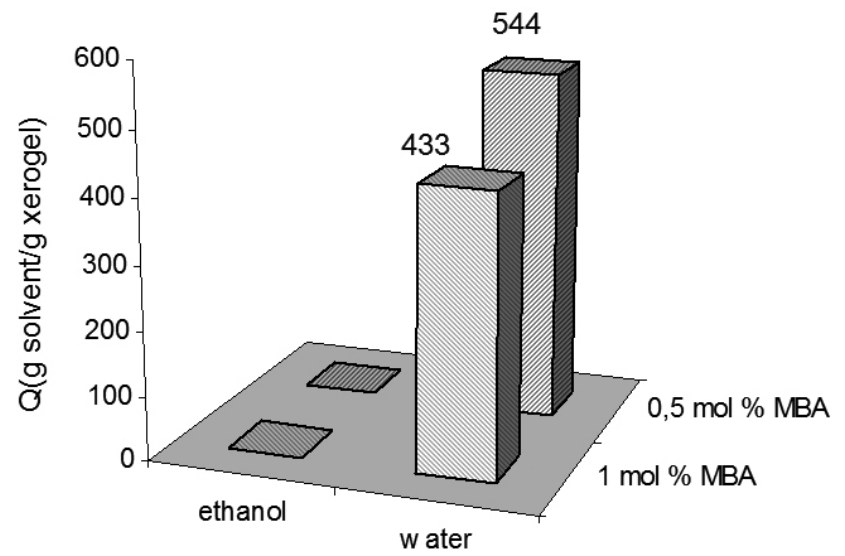

Figure 8. Absorption (Q) of poly(AA-co-NNDMAAm) 3:1 / 1 mol$\% \mathrm{MBA}$ and $0.5 \mathrm{~mol}-\% \mathrm{MBA}$ in twice-distilled water and ethanol at room temperature.

Effect of $p H$ on absorbency

To investigate the influence of $\mathrm{pH}$ on the degree of gel swelling, the $\mathrm{pH}$ was adjusted with $1 \mathrm{M} \mathrm{HCl}$ or $1 \mathrm{M} \mathrm{NaOH}$, from $\mathrm{pH} 1$ at $\mathrm{pH} 9$. Figure 9 shows the effect of the $\mathrm{pH}$ values of the solutions, on the swelling behaviour for all the studied copolymers. The absorption curve shows an optimal value at $\mathrm{pH} 5$, when the feed monomer ratio is $3: 1$ with 1 and 0.5 mol-\% MBA. From $\mathrm{pH} 1$ to $\mathrm{pH} 5$, absorbency increases for all copolymers; at higher $\mathrm{pH}$, the absorbency remains constant for all the comonomer ratios. 


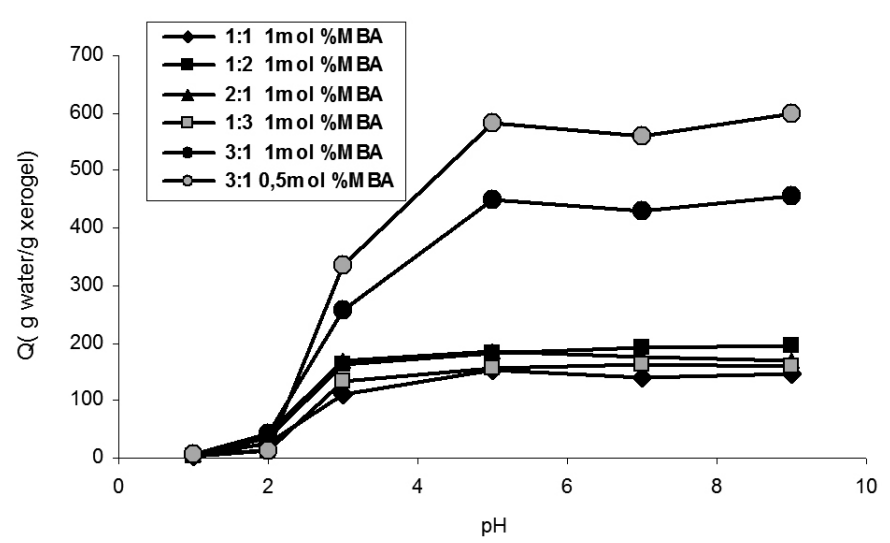

Figure 9. Absorption (Q) of poly (AA-co-NNDMAAm) $1: 1 ; 1: 2 ; 2: 1$; $1: 3 ; 3: 1 / 1$ mol- $\%$ MBA and ratio 3:1 0.5 mol- $\%$ MBA in water at room temperature for $\mathrm{pH} 1,3,5,7$, and 9 .

Effect of the temperature on absorbency

The effect of the temperature on the absorbency and water loss, for poly(AA-co-NNDMAAm) for these feed mol ratios, is shown in Figure 10 and 11 respectively. It demonstrates that the absorbency increases as increases the temperature until $50^{\circ} \mathrm{C}$ for the copolymer cross-linked with $0.5 \mathrm{~mol}-\%$ of MBA. For the copolymer 3:1 to 1 mol- \% MBA the absorbency increases as increases de temperature until $30^{\circ} \mathrm{C}$. It is due to the smaller amount of crosslinking incorporated into the backbone.

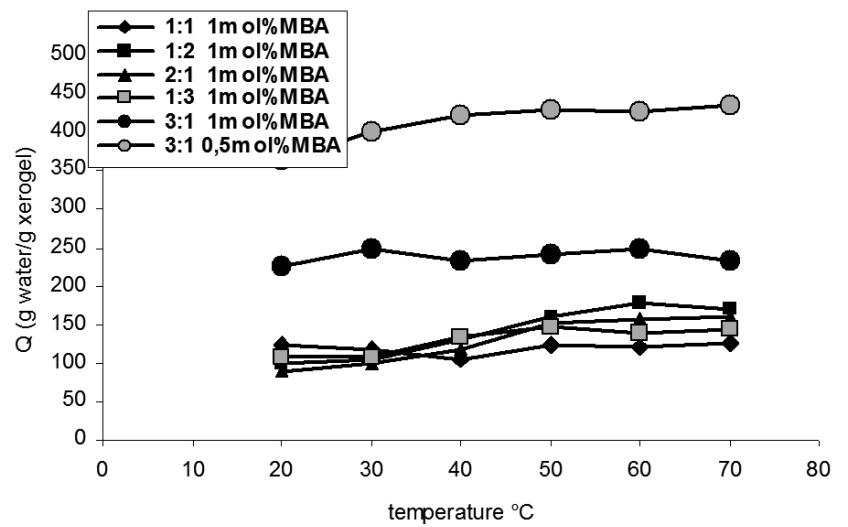

Figure 10. Absorption (Q) of poly(AA-co-NNDMAAm) $1: 1 ; 1: 2 ; 2: 1 ; 1: 3$; $3: 1 / 1 \mathrm{~mol}-\% \mathrm{MBA}$ and ratio $3: 10.5 \mathrm{~mol}-\% \mathrm{MBA}$ at different temperatures.

At higher temperatures, water loss is significant in comparison with the copolymers with higher percentages of cross-linking; at $60^{\circ} \mathrm{C}$, water is completely removed for all copolymers $60^{\circ} \mathrm{C}$.

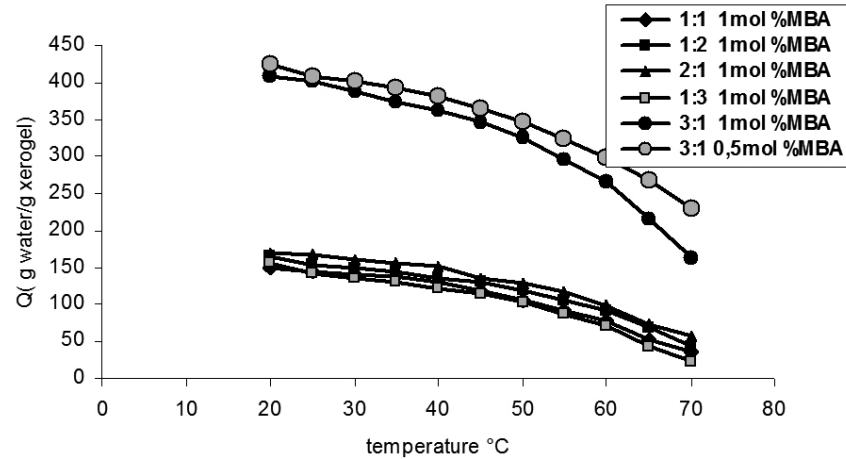

Figure 11. Water loss (Q) of poly(AA-co-NNDMAAm) $1: 1 ; 1: 2 ; 2: 1 ; 1: 3$; $3: 1 / 1$ mol- $\%$ MBA and ratio $3: 10.5 \mathrm{~mol} \% \mathrm{MBA}$ at different temperatures for 24 hours.

Effect of salt solutions on absorbency

Figure 13 shows the effect of the concentration of the salt solution on the absorbency of poly(AA-co-NNDMAAm). The results indicate that this polymer's absorbency depends on the different $\mathrm{NaCl}$ concentrations and on the copolymer composition. By increasing the saline concentration, the absorbency in all comonomer ratios decreases. As the amount of ionized groups in the hydrogel increases, absorbency decreases. It can be corroborated by ratio 3:1 of poly(AA-co-NNDMAAm) 1 and 0.5 mol- $\%$ MBA.

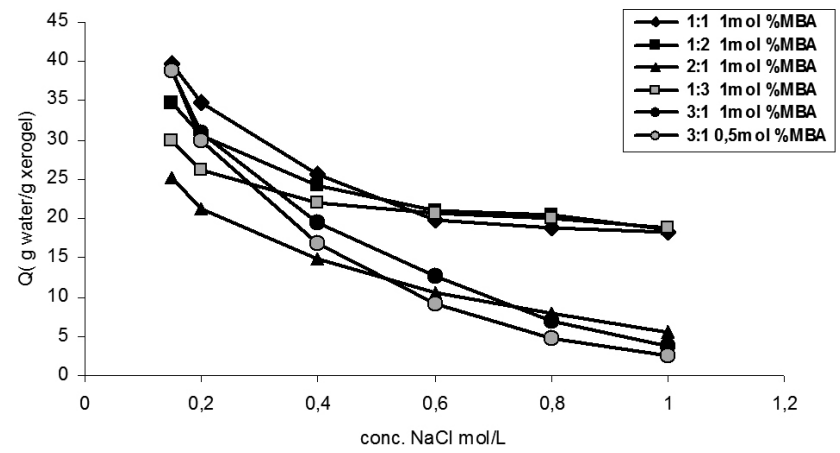

Figure 12. Absorption (Q) of poly(AA-co-NNDMAAm) 1:1; 1:2; 2:1; $1: 3 ; 3: 1 / 1$ mol-\% MBA and ratio $3: 1,0.5$ mol- $\%$ MBA at room temperature for different $\mathrm{NaCl}$ concentrations.

\section{CONCLUSIONS}

Hydrogels of AA and NNDMAAm were prepared in aqueous solution and the swelling properties were studied. The results showed that the poly(AAco-NNDMAAm) 1 mol- $\%$ MBA feed monomer ratio 3:1, presents the highest absorption in twice-distilled water.

The study of the effect of the amount of cross-linked of poly(AA-coNNDMAAm) 3:1 indicated that on reducing the amount of cross-linked from 1 mol- $\%$ to $0.5 \mathrm{~mol}-\%$, absorption in twice-distilled water, increases. This result can be attributed to the fact that the material is less rigid and less compact.

The study of absorption at different $\mathrm{pH}$, indicated that all the synthesized copolymers poly(AA-co-NNDMAAm) present a maximum absorption close to a neutral $\mathrm{pH}$. The absorbency at neutral $\mathrm{pH}$ of the ratio $3: 1$, reached $544 \mathrm{~g}$ water / $\mathrm{g}$ xerogel and $433 \mathrm{~g}$ water / $\mathrm{g}$ xerogel when the cross-linking reagent was $0.5 \mathrm{~mol}-\%$ and $1 \mathrm{~mol}-\%$ respectively.

Absorbency capacity of all comonomer ratios of poly(AA-co-NNDMAAm) increases as the temperature increases up to $30-50^{\circ} \mathrm{C}$ range.

The saline concentration increases the ionic strength, producing a screening of the charges present in the polymer chain, producing a lower waterabsorption.

The contact angle values are higher for the copolymers richest in the less hydrophilic moiety because the copolymer material presents lower compatibility with water. 


\section{ACKNOWLEDGEMENTS}

The authors thanks to Fondecyt $N^{\circ} 1050572$. B.L. Rivas thanks to CIPA.

\section{REFERENCES}

1. W.F. Lee, W.H. Chaing, J. Appl. Polym. Sci; 91, 2135 (2004).

2. Y. Zhao, H. Su, L. Tianwei, Polymer. 46, 5368 (2005).

3. S. Wasim Ali, S. Raza Zaidi, J. Appl. Polym. Sci. .98, 1927 (2005).

4. B. Rojas de Gascue, M. Ramírez, R. Aguilera, J.L. Prin, C. Torres, Revista Iberoamericana de Polímeros 7, 3 (2006).

5. X.Ma, Y Xing, Polym. Bull. 57, 207 (2006).

6. A.Ozdagan, O.Okay, , Polym. Bull. 54, 435 (2005).

7. Y. Zhang, F. Wu, M. Li, E. Wang, Polymer. 2, 1 (2005).

8. J. Jovanovic, B. Adnadjevic, Polym. Bull. 58, 243 (2007) .

9. L. F. Gudeman, N. A. Peppas, J. Membr. Sci. 107, 239 (1995).

10. A. Shefer, A.J. Grodzinsky, K.L. Prime and J.P. Busnel, Macromolecules 26, 5009 (1993).

11. G. Eichenbaum, P. Kiser, A. Dobrynin, S. Simon and D. Needham, Macromolecules 32, 4867 (1999).

12. O.B.Ozum, S Kundakci,E.Karadag, Polym. Bull. 57, 703 (2006)

13. S. Tomic, E.H. Suljovrujic, Y. M. Filipovic, Polym. Bull. 57, 691 (2006).

14. I. Katime, V. Saéz, E. Hernáez, Polym. Bull. 55, 403 (2005).

15. S.A.Pooley, B.L.Rivas, A.Cárcamo, G. del C Pizarro, J.Chil.Chem.Soc.
53,1483 (2008)

16. K. Pagonis, G. Bokias, Polym. Bull. 58, 289 (2007).

17. W.S.Ali, S.A. Zaidi, J. Appl. Polym. Sci. 98,1927 (2006).

18. H.D. Schild, Progr Polym Sci. 17, 163 (1992).

19. A. Ozdagan, O.Okay Polym Bull 54,435 (2005)

20. K.Pagonis, G. Bokias Polym Bull 58,289 (2007)

21. S.Çavuş , G.Gürdağ Polym Bull 58,235 (2007)

22. Ch.Xu, J.Kopeček J Polym Bull 58,53 (2007)

23. D. Kuckling, H.J. Adler, L. Ling, W.D. Habicher, K.F. Arndt, Polym. Bull. 44, 269 (2000).

24. C. Wu, S. Zhou, Macromolecules 28, 8381 (1995).

25. G. Chen, AS. Hoffman, Macromol Chem Phys 196, 1251 (1995).

26. M. Shibayama, Y. Suetoh, S. Nomura, Macromolecules 29, 6966 (1996).

27. J.C. Sanchez, A. Martinez, P Ortega, A. Gonzales, E. Mendizábal, J. E. Puig, Polym. Bull. 56, 437 (2006).

28. M.Jeria, G del C Pizarro, O. Marambio, M. Huerta, P.Valencia, B.L.Rivas J Appl Polym Sci 98,1897 (2005)

29. S.A.Pooley, B.L.Rivas, F.J.Riquelme J.Chil. Chem. Soc. 52, 1, 088 (2007)

30. S.A.Pooley, B.L.Rivas, A. Cárcamo, G del C Pizarro $J$ Chem Soc $\mathbf{5 3}, 1483(2008)$

31. F. Tüdös, T. Kelen, B. Turcsanyi, J. Polym. Sci: Polym. Chem. Ed. 19, 1119 (1981) 